\title{
Using a Two-Dimensional Mean Value Matrix (TDMVM) to Improve Users' Satisfaction with Government e-Recruitment Website
}

\author{
Chun-Ming Yang1, Neng-Yih Shin², Ming-Wei Weng³, Chang-Hsien Hsu* ${ }^{*}$ \\ ${ }^{1}$ Department of Management Sciences, Tamkang University, Taiwan, R.O.C. \\ 2 Department of Computer Science and Information Engineering, Asia University, Taiwan, R.O.C. \\ ${ }^{3}$ Department of Industrial Engineering and Systems Management, Feng Chia University, Taiwan, R.O.C. \\ ${ }^{4}$ Department of Business Administration, Asia University, Taiwan, R.O.C \\ * Corresponding author. email: pci@asia.edu.tw \\ Manuscript submitted March 15, 2014; accepted July 18, 2014.
}

\begin{abstract}
The purpose of this study is to examine the relationship between local government services and the overall satisfaction of users with the e-recruitment website (e-job website) in Taiwan. A two-dimensional mean value matrix (TDMVM) technique was used to explore the identification, classification, and application of website service quality. The results show that the asymmetrical relationship between local government services and the overall satisfaction of users with the e-job website can be confirmed in relation to 22 service attributes. 5 of the 22 service quality attributes were shown to be the top priorities for improvement. Therefore, managers should be aware that the service quality of e-job websites needs to be improved.
\end{abstract}

Key words: E-recruitment website, e-job, service quality, two-dimensional mean value matrix (TDMVM).

\section{Introduction}

Recently, numerous studies have been carried out on the service of electronic government. Electronic government (e-government) is becoming an important tool for improving efficiency and enhancing management quality in government administration and public services [1]. E-government provides several benefits in terms of reducing the unemployment rate, being cost effective, providing fast services, and return on investments [2]. Beynon-Davies and Martin [3] evaluated the efficiency of e-government policy in implementing local e-government in the UK. Subsequently, King and Cotterill [4] explored the potential of technology to transform the relationship between citizens and local government service providers. The number of countries employing local e-government services began to increase, due to the apparent benefits of doing so. Among the 192 countries surveyed for local e-government development by the United Nations (UN), there was not one country that did not employ some form of local e-government [5]. An important point to emphasize here is that local e-government policies have made other countries more convenient for citizens around the world.

Nearly 30 years later, more unemployed individuals use the Internet to search for jobs, half of which do so using online access at home; Internet search rates have exceeded those of such traditional methods such as the services of private employment agencies, contacting friends or relatives, and using the registers of 
unions or professional organizations. Cappelli [6] noted that approximately $90 \%$ of all large US-based enterprises used the Internet as a recruitment tool. Given this, senior managers and human resources personnel need to consider electronic recruiting (e-recruitment) as an integral part of their corporate strategy. E-recruitment websites (for government and non-profit organizations) have undergone considerable growth and the number of job seekers who conduct job searches over the Internet has increased in all areas except for private enterprises. Hence, the growing use of e-recruitment is becoming the primary method for marketing jobs in an increasingly world-wide labor market. The application of e-recruitment to government services has also given rise to local e-government websites.

Presently, e-recruitment, as an electronic services (e-services) application, has been adopted in many organizations, from large organizations to smaller companies, even in Taiwan. Rust and Lemon [7] have pointed out that e-services are providing consumers with a superior experience with respect to the interactive flow of information. Therefore, it is essential for governments to evaluate and enhance the service quality of local government recruitment websites (e.g. e-job websites in Taiwan) in order to enhance national competitiveness in relation to the development of e-services and an information society across Asia. In general, the recruitment service provided on these websites is free for job seekers, who can enjoy the service once they have become members of the website. However, job seekers can be unhappy with the service provided by a recruitment website, and may look for other websites that fulfill their expectations for service quality. Therefore, good service quality of e-recruitment websites has become more and more important. Moreover, good websites also allow both job seekers and potential employees to efficiently search jobs in relation to 1) posting resume profiles 2) posting jobs and 3) searching for resumes or jobs using specific criteria that limit the search output. It is important for managers to understand how to evaluate product or service improvement efforts. In relation to this, a two-dimensional mean value matrix (TDMVM) technique is an easy, useful and understandable guide for identifying the most crucial product or service attributes in terms of their need for managerial action, as a means to develop successful marketing programs and achieve a competitive advantage.

In order to investigate the expectations placed on different attributes in relation to the overall performance of job seekers on the recruitment website, this study adopted a quantitative approach based on a TDMVM approach, following the work of Martilla and James [8]. The TDMVM technique has been widely applied in measuring and monitoring product/service quality across various industries. Hu et al. [9] proposed a modified TDMVM model that combines a back-propagation neural network (BPNN) and decision making trial and evaluation laboratory (DEMATEL) in order to evaluate quality importance and priority of improvement, with less resource inputs for problem resolution in the computer industry. Coghlan [10] applied the TDMVM approach in order to identify how reef tourism attributes influence visitor satisfaction, in particular those satisfaction-generating attributes and dissatisfaction-generating attributes within the reef tourism experience. Lo et al. [11] used the TDMVM approach in order to construct a series of nano-product importance attributes and performance evaluation maps so as to understand and identify areas for improvement. Chang [12] adopted the TDMVM approach in order to build a management mechanism that continuously measures and improves the quality of Public Employment Services (PESs). Lemieux et al. [13] presented a comparative case study of federal and state land and natural resource manager perceptions of agency performance on factors influencing adaptive capacity on climate change in northern Colorado and southwestern South Dakota. Chen [14] combined zone of tolerance of expectation (ZOT) and TDMVM approaches in order to evaluate service quality attributes and prioritize attributes for improvement in a Taiwanese hot springs hotel.

The purpose of this study is to explore and measure users' acceptance of local government recruitment websites (e-job website) in Taiwan from the perspective of users through the analysis of TDMVM. This 
study therefore aims to construct a series of e-job websites' importance attributes and performance evaluation maps and provide a focus on e-recruitment website improvement activities, which has not yet been examined in the literature. There is clearly a need for a simple and easy approach to determine the weaknesses of e-job websites, for the purpose of continuous service improvement. By identifying the needs and requirements of users on e-recruitment websites (e-job websites) in Taiwan, e-job websites' managers will be in a better position to build a competitive advantage and to develop appropriate marketing strategies for their target users.

The remainder of the paper is organized as follows. The next section presents a literature review of the development of e-recruitment and service quality. Section III describes the methodology used in this study, and includes questionnaire constructs and measures, statistical analysis methods, and the TDMVM approach. The empirical analysis is described in Section IV. In the final section the conclusions are discussed.

\section{Literature Review}

\subsection{Development of e-Recruitment}

With the blooming of the Internet, the number of Internet users increased rapidly. In such a rapidly changing environment, achieving the best value for e-recruitment solutions can be challenging. The past decade has seen a marked trend towards e-recruitment, especially among large, public sector organizations, where budget allocations for such processes are limited. Gradually, e-recruitment has become one of the most successful Internet applications as a method for quickly reaching a large pool of potential job seekers.

The early development of e-recruitment can be traced back to articles from the mid-1980s, while systematic reference to e-recruitment in human resource (HR) journals began almost a decade later, in the mid-1990s, when IT companies and universities began to use the Internet extensively [15]. E-recruitment refers to the process whereby employers are able to electronically advertise jobs, scan and store resumes, conduct tests, and contact qualified applicants using the power of the Internet to match people to jobs [16]. For job seekers, an e-recruitment website provides a unique opportunity to explore constantly updated employment opportunities through an extensive database of jobs. Job seekers can then post their resumes online and announce their availability to potential employers since the emergence of the job board. On the one hand, the increasing accessibility of the Internet seems to require an increase in investment in online advertising. On the other hand, the decreasing ease of finding qualified applicants has shifted the strategic focus of many organizations towards better utilizing their own websites [6], [17].

\subsection{E-Government Applications in Taiwan: E-Job Websites}

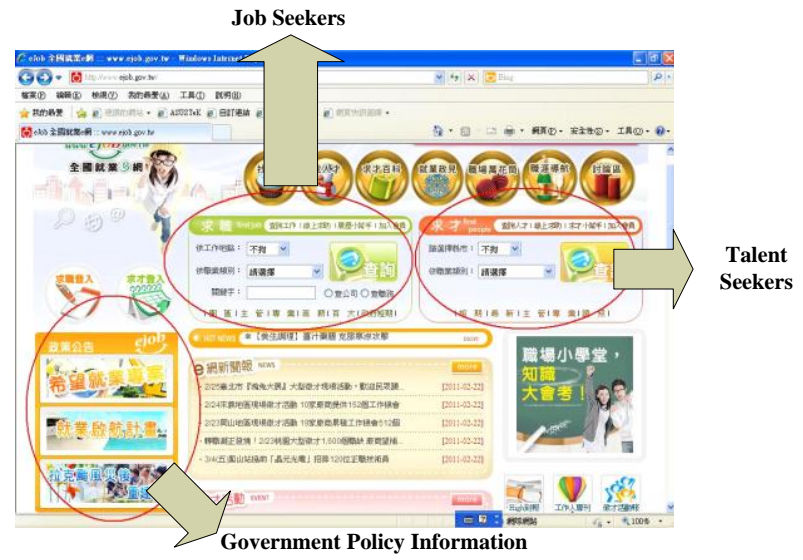

Fig. 1. E-government service of Taiwan's e-job website. 
In Taiwan, the public sector is distinct from the private sector and so the government is ramping up more information about public sector jobs, government grants, and job fairs in the recession. The e-job website [18] is illustrated in Fig. 1.

E-job is the largest official employment service website in Taiwan. With the most extensive database of job opportunities in public affairs, medical treatments, education and non-government organizations, the objective of e-job is to be the only professional HR site that completely integrates official and non-governmental job opportunities. E-job also offers information about unemployment training and unemployment grants. The Employee Service Center offers job seekers a face-to-face interview in the physical environment. Moreover, e-job also offers a job clearing system for job seekers. By using this system, job seekers can send or update personal information, post job vacancies, search for job opportunities, apply online and seek advice from the ministry. It also offers a one-stop service for job registration and matching. Definitions and descriptions of procedures used by the e-job website are illustrated in Fig. 2.

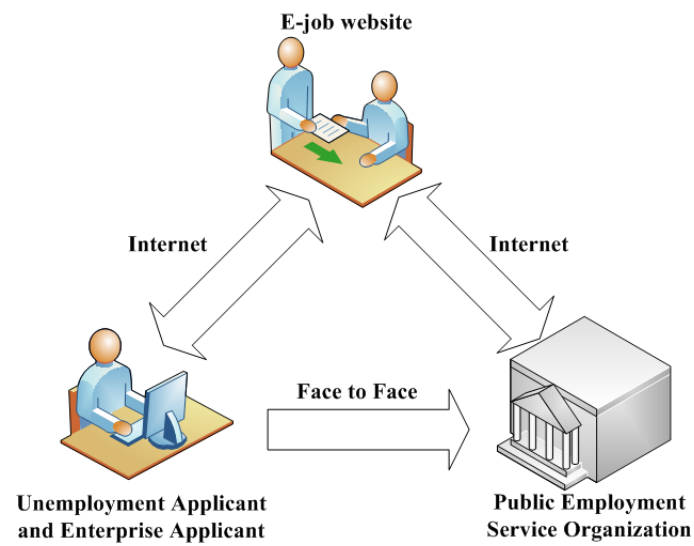

Fig. 2. Definitions and description of procedure for e-job websites.

The framework of e-job should be explained before the satisfaction of users is measured. The planning framework of e-job by the Bureau of Employment and Vocational Training is divided into seven parts [19].

- E-Human Resource (E-HR): The government's E-HR system plays an important role in ensuring free and open access to the world's database, including job opportunities, documenting the work of our democracy and providing resources for connecting with government agencies at all levels, in the wake of employment policies and local government laws.

- Online free service: Private employment sites often charge job seekers to search for job opportunities and companies to find candidates. Therefore they widely use a webpage featuring online classified advertisements. Interested subjects were directed to the 104 job bank. On the contrary, the objectives of e-job are to offer efficient, high quality, free online services to both citizens and businesses.

- Market segmentation: E-job's users are divided into target groups in terms of identity, including aborigines, elderly citizens, the handicapped, foreign spouses, and the powerless. Therefore, e-job also provides public sector jobs such as military service, opportunities for public school teachers and private job opportunities.

- Public sector jobs: E-job offers job seekers examination information and official job opportunities.

- Bringing to light government recruitment policies: E-job offers unemployed individuals and employers the latest information on government recruitment for the realization of sufficient employment and the stimulation of the domestic economy.

- Auto-trace service for job seekers: E-job offers job seekers a complete range of call center services, a take care message, and employment assistance such as online job matching. 
- Click-and-Mortar service: E-job has worked with the Public Employee Service Center for years, and has consisted of four main parts: 1) The e-job system clears personal data automatically for job seekers and employers; 2) A call center takes care of job seekers and offers employment services; 3) A Public Employee Service Center offers job seekers and employers a job matching service via e-job; and 4) E-job integrates employment information from the local Public Employee Service Center in order to reach the goal of local employment development.

\subsection{Service Quality}

Several studies have pointed out that a business with high service quality will increase its customer satisfaction while retaining customer loyalty [20]. However, Chen et al. [21] have noted that there is a nonlinear relationship between service quality and customer loyalty. Hence, the continuous improvement of certain quality attributes does not determine user satisfaction.

Parasuraman et al. [22] developed a scale for measuring service quality, which is widely popular and is known as the SERVQUAL scale. This scale operationalized service quality by evaluating both in relation to the 22 items that represent five service quality dimensions. These are known as "tangibles", "reliability", "responsiveness", "assurance" and "empathy". The five dimensions are schematized in Table 1. Fundamentally, several researchers have proposed that the SERVQUAL scale is sufficient in relation to assessing service quality [23]. They also suggest that SERVQUAL must be customized to the specific service sector in which it is applied. Summarizing the above results, we establish the following methodology for measuring the service quality of the e-job website.

Table 1. The Five Dimensions of Service Quality

\begin{tabular}{cl}
\hline \hline Dimension & Definition \\
\hline Tangibles & The appearance of physical facilities, equipment, personnel and written materials \\
Reliability & $\begin{array}{l}\text { The ability to perform the promised service both dependably and accurately } \\
\text { Responsiveness }\end{array}$ \\
Assurance & $\begin{array}{l}\text { Employees' knowledge and courtesy and their ability to inspire both trust and confidence } \\
\text { Caring, easy access, good communication, customer understanding and individualized } \\
\text { attention given to customers }\end{array}$ \\
\hline \hline
\end{tabular}

Source: Adapted from Parasuraman et al. [8]

\section{Methodology}

\subsection{Questionnaire Constructs and Measures}

The questionnaire and interview questions were designed by Parasuraman et al. [22] in order to test various propositions derived from the HRM/Strategic and HRM literature. Based on a literature review, six service quality items that are fundamental to the success of e-government websites were identified and reported [24]. Alanezi et al. [25] have presented a general framework in order to review the methods, findings and instructional issues related to e-government service quality. The questionnaire and interview attributes were identified and adopted from the work of past researchers [24, [26]-[29].

The questionnaire is divided into two parts. Part 1 shed light on the evaluation of job seekers satisfaction with the e-job website. The method of evaluation is related to the format of the questionnaire. In general, there are 22 questions and five dimensions in a questionnaire. We use a five-point Likert scale to represent the degree of satisfaction, from 1 being "Very Dissatisfied" to 5 being "Very Satisfied"; and importance from 5 being "Very Important" to 1 being "Not Important", respectively. Part 2 presents the basic information of job seekers, mainly to analyze the characteristics of job seekers, and their demographic variables, and 
consists of six attributes: gender, age, level of education, latest income, job-seek resources and e-job web feed.

\subsection{Statistical Analysis Methods}

We collected data through a personal survey based on a structured questionnaire that was tested on a sample of job seekers from the Employee Service Center (Taichung-Changhua-Nantou Region) during class time. Data collection sessions each lasted about one hour and were conducted at roughly one-week intervals. Furthermore, in order to ensure validity and reliability, we pre-tested the questionnaire using the responses of thirty randomly selected respondents in the study. In order to assess the quality of each scale, we computed the Cronbach's alpha measure of internal consistency of a scale [30]. The questionnaire was piloted using three HR professors with recruitment experience at a global enterprise. Several minor modifications were made to the questionnaire at this stage. Rafaeli [31] has noted that those respondents who have never used an E-job website or those with low frequency use can be ignored. These respondents were asked to access the survey on the use frequency of e-job websites (http://www.ejob.gov.tw/).

This study used SPSS for Windows (version 17.0). The descriptive statistics were computed. Furthermore, reliability as a measure of internal consistency, independent-sample t-tests, and one-way analysis of variance (One-way ANOVA) were calculated. The next section briefly describes the TDMVM approach.

\subsection{Two-Dimensional Mean Value Matrix (TDMVM)}

TDMVM is a powerful tool, which has been successfully applied in the measurement of service quality of e-job websites. Martilla and James [8] have presented a simple but effective technique, TDMVM, in order to analyze product attributes. TDMVM has been widely applied to study customer satisfaction expressed as a function of both expectations related to importance (X-axis) and performance (Y-axis). A set of attributes pertaining to a particular service (or good) are evaluated on the basis of how important each is to the customer, and how the service/good is perceived in relation to the performance and importance of each attribute. Therefore, interpretations of the importance-performance grid are created, and each quadrant is given a corresponding action strategy (see Fig. 3).

- Quadrant I, called "Keep up the Good Work", suggests retaining current action strategies.

- Quadrant II, titled "Concentrate Here", suggests taking action to change client perceptions of the attributes in this quadrant.

- Quadrant III, called "Low Priority", suggests that little effort should be focused on actions influencing either the importance or performance of the attributes in this quadrant as the visitor has little concern for these attributes.

- Quadrant IV, titled "Possible Overkill", suggests that efforts focused on these attributes can be reduced.

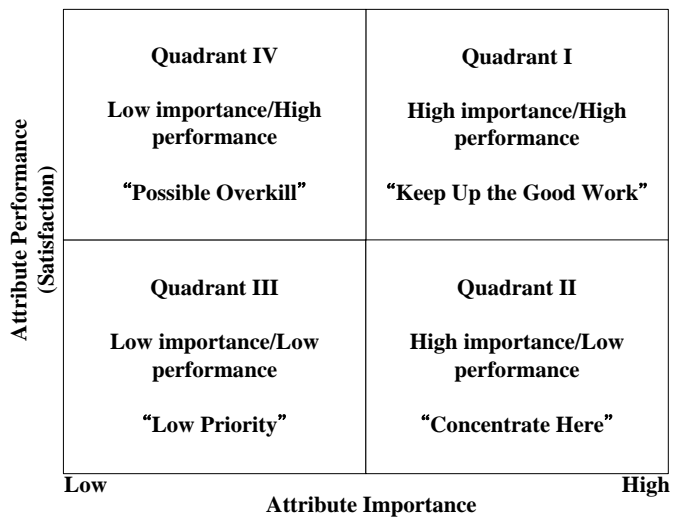

Fig. 3. Two-dimensional mean value matrix (TDMVM). 


\section{Results}

\subsection{Statistical Analysis Results}

Comprehensive data collection from the Employee Service Center (Taichung-Changhua-Nantou Region) during promotion employment class hours resulted in a total of 180 questionnaires between January 1 , 2011 and January 30, 2011. 160 questionnaires were returned, which represents a return rate of 88.9\%. 130 valid questionnaires were returned, with a rate of $72.7 \%$. Among these, females accounted for $66.9 \%$. People aged 26-35 years accounted for 58.5\% of the sample. Undergraduates accounted for $42.3 \%$. An income of less than NTD 20,000 accounted for 36.9\%. An income of NTD 20,001-30,000 accounted for $35.4 \%$. All participants had basic Internet navigating experience, and were considered potential users of e-recruitment websites. In fact, $73.1 \%$ indicated that they preferred e-recruitment to traditional recruitment. Web feeds about e-job accounted for 37.7\%; and employee service centers accounted for $36.2 \%$.

The reliability of satisfaction and the importance of service attributes for the pre-test of 30 questionnaires were measured using Cronbach's alpha and resulted in values of 0.953 and 0.957, respectively. Subsequently, a post-test was conducted with 130 valid questionnaires, and Cronbach's alpha results of 0.976 and 0.954 were found in the reliability of satisfaction and the importance of service attributes, respectively, which exceeds the recommended value of 0.70 for social science research [32]. On the other hand, content validity must also be discussed in this study, which provides evidence about the degree to which the attributes of the assessment instrument are relevant to and representative of the targeted construct. The attributes representing the various constructs of an instrument are substantiated by a comprehensive review of the relevant literature. Next, we examined whether various demographic groups differed with regard to the six variables of interest. Moreover, independent samples t-tests and a series of ANOVA indicated that age, level of education and latest income did not significantly impact on different perceptions regarding satisfaction and importance for e-job's service attributes.

\subsection{Application of the Two-Dimensional Mean Value Matrix (TDMVM)}

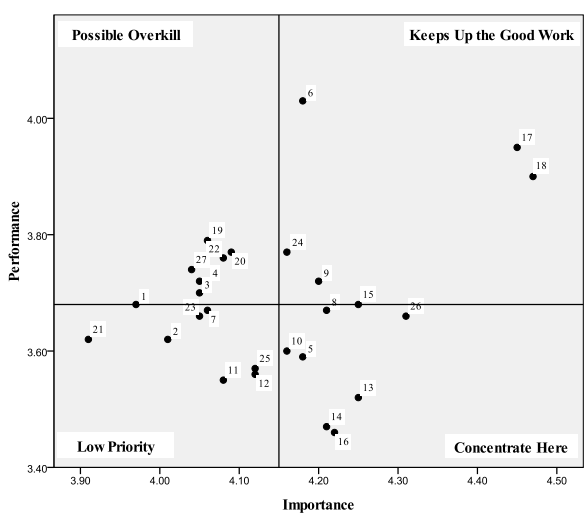

Fig. 4. TDMVM with attribute ratings for e-job website.

In this section, an examination of the content of the final items making up each of SERVQUAL's five dimensions (suggested in Table 2) summarizes mean scores for the "importance" of and "satisfaction" with e-job. According to Table 2, we are able to obtain an insight into what HR managers in the public sector perceive to be important in relation to good service quality of e-recruitment: 18. "Assuring the accuracy of job opportunities and information (mean $=4.47$ )" tends to be considered the most important, and 6. "The internet provides a 24 -hour assistant services (mean $=4.03$ )" is perceived as the top satisfaction. On the 
other hand, 21. "Providing an online call center (web services) (mean $=3.91$ )" is found to be the least important, and 16. "Searching for the ideal job quickly (mean $=3.46$ )" is ranked lowest on the satisfaction scale. Furthermore, the overall importance of service attributes was measured using 5 dimensions with a mean of 4.15. The overall satisfaction with service attributes was measured using 6 attributes with a mean of 3.68. Obviously, e-job service quality is necessary to improve user satisfaction.

Table 2. Aggregate Performance and Importance Scores of Each Attribute for e-Job

\begin{tabular}{|c|c|c|c|}
\hline Extracted dimension & Service attributes & IAV & SAV \\
\hline \multirow{6}{*}{ 23. Tangibles } & 1. Inquiring about online job opportunities quickly & 3.97 & 3.68 \\
\hline & 2. Information richness on the web & 4.01 & 3.62 \\
\hline & 3. Browsing the web easily & 4.05 & 3.70 \\
\hline & 4. Executing Web Service Function Operations easily & 4.05 & 3.72 \\
\hline & 5. Providing online information for manufacturers & 4.18 & 3.59 \\
\hline & Average & 4.05 & 3.66 \\
\hline \multirow{5}{*}{ 24. Reliability } & 6. Providing a 24-hour assistance service & 4.18 & $@ 4.03$ \\
\hline & 7. Responding immediately after resume registration & 4.06 & 3.67 \\
\hline & 8. Providing a speedy and steady web browser & 4.21 & 3.67 \\
\hline & 9. The web cannot shutdown suddenly while inputting data & 4.20 & 3.72 \\
\hline & Average & 4.16 & 3.77 \\
\hline \multirow{5}{*}{ 25. Responsiveness } & 10. Responding accurately to a user's problem & 4.16 & 3.60 \\
\hline & 11. Being a good custom claim provider & 4.08 & 3.55 \\
\hline & 12. Responding quickly to a user's problem & 4.12 & 3.56 \\
\hline & Average & 4.12 & 3.57 \\
\hline & 13. Providing high-accuracy job matching & 4.25 & 3.52 \\
\hline \multirow{5}{*}{ 26. Assurance } & 14.Searching for a job quickly & 4.21 & 3.47 \\
\hline & 15. Providing more job opportunities & 4.25 & 3.68 \\
\hline & 16. Searching for the ideal job quickly & 4.22 & $\star 3.46$ \\
\hline & 17. Assuring the confidentiality of personal data & 4.45 & 3.95 \\
\hline & $\begin{array}{l}\text { 18. Assuring the accuracy of job opportunities and } \\
\text { information }\end{array}$ & $@ 4.47$ & 3.90 \\
\hline \multirow{7}{*}{ 27. Empathy } & Average & 4.31 & 3.66 \\
\hline & 19. Providing job seekers with a call center for hiring & 4.06 & 3.79 \\
\hline & 20. Providing job seekers with mail & 4.09 & 3.77 \\
\hline & 21. Providing an online call center (Web Services) & $\star 3.91$ & 3.62 \\
\hline & 22. Contacting with call center is easy & 4.08 & 3.76 \\
\hline & Average & 4.04 & 3.74 \\
\hline & Total Average & 4.15 & 3.68 \\
\hline
\end{tabular}

Note: IAV: important average value; SAV: satisfaction average value bold designed preferential improvement areas; @ designed high importance/high satisfaction; $\star$ designed low importance/low satisfaction.

TDMVM was used to evaluate user demand and e-job service quality. The mean importance and performance ratings for the 22 service attributes are presented in Fig. 4. The means of performance and importance divide the matrix into four quadrants. There are a number of possible explanations for the TDMVM with examples taken from each of the four quadrants. The analysis yields the following description:

- Quadrant I (High importance/High performance) - Items 6, 9, 15, 17, 18 and 24 fell within "Keep Up the Good Work", which implies that job seekers were satisfied with e-job while searching for jobs. HR managers in the public sector keep inputting resources for improving e-job service quality.

- Quadrant II (High importance/Low performance) -Items 5, 8, 10, 13, 14, 16 and 26 are categorized as 
"Concentrate Here", which indicates that service quality attributes have a higher importance degree, but a lower satisfaction level. The e-job's user is dissatisfied with these attributes, which reduces the evaluation of user satisfaction. HR managers in the public sector need to take improvement actions here in order to better the performance of these attributes.

- Quadrant III (Low importance/Low performance) -Items 2, 7, 11, 12, 21 and 25 are classified as "Low Priority" which indicates that HR managers in the public sector do not need to pay much attention to these attributes, since users pay are less concerned with them.

- Quadrant IV (Low importance/High performance): Items 1, 3, 4, 19, 20, 22 and 27 are recognized as "Possible Overkill" which means that customers are less concerned with these attributes, but that the performance of e-job exceeds users' expectations.

\section{Conclusions}

Over the past few years, the Internet has dramatically changed the face of the employment environment. e-recruitment can be viewed as the newest recruitment method. Moreover, Vidot [33] suggests that e-recruitment refers to the use of the Internet to attract high quality candidates. Therefore, the functions of e-recruitment websites directly affect business performance. On the other hand, these also indirectly affect the implementation of government policy, the business expansion period and shorten unemployment and switching periods. The aim of this paper is to detect significant differences between the different characteristics of job seekers, the importance of e-job service attributes and user satisfaction with e-job service attributes.

This study adopts the TDMVM technique to measure the service quality of the online e-job website. We also discuss how the e-job website assists job seekers in finding a new job more effectively. These also indirectly affect the implementation of government policy, the business expansion period and shorten unemployment and switching periods. Moreover, significant differences are detected between the different characteristics of job seekers, the importance of e-job service attributes and the satisfaction of users with e-job service attributes. It is clear from Table 2 that overall importance (mean $=4.15$ ) lies between important and most important, and overall satisfaction (mean $=3.68$ ) lies between general satisfaction and satisfaction. Moreover, the results also imply that an asymmetrical relationship between local government services and the overall satisfaction of users with e-job can be confirmed in relation to 22 service attributes. Finally, improvement strategies for the e-job website should focus on top-priority service items, "Concentrate Here" items, and the "Possible Overkill" service attributes shown in Fig. 4.

The results of this study have several managerial implications regarding the improvement and development of e-job websites for local government e-recruitment. Some effective strategies to improve and control the six top-priority improvement items, which fell within the "Concentrate Here" area, were proposed; for example, at least six strategies might be considered:

1) "Providing online information for manufacturers" - Job seekers expect to obtain more complete information from manufacturers on e-job. Therefore, e-job can provide more detailed information, such as company size, company products, services, welfare system and a theory of business. On the other hand, strengthening communication between manufacturers and e-job is needed to further update new information.

2) "Providing a speedy and steady web browser" - Users expect to a browser that is both speedy and steady. Hence, performing e-job system maintenance is required and the administrator should inform users when this takes place in order to avoid complaints and enable users to use e-job more effectively.

3) "Responding accurately to a user's problem" - With a strong focus on call center operations and 
familiarity, service specialists should focus on solving job seekers' problems.

4) "Providing high-accuracy job matching" - Job seekers expect high-accuracy job matching and meticulous designing of the e-job system column. Hence, e-job system developers could develop an artificial intelligence engine to match profiles with pre-qualified job opportunities.

5) "Searching for a job quickly" - Developing an unemployment trace policy for job seekers on e-job. In the meanwhile, making an assistant referral to the Public Employee Service Center.

6) "Searching for the ideal job quickly" - e-job should display job opportunities that match the skills and desires of job seekers while providing more detailed information on certification and training programs for shortening the unemployment or switching periods.

For the reasons mentioned above, service quality attributes in this study have demonstrated that e-job websites can be practically implemented and can provide adequate results. The introduction of the TDMVM technique can effectively guide local government to improve quality attributes. Thus, continuous improvement is considered one of the important quality activities for e-job websites to pursue the best quality for job seekers. Website managers are required to continuously strengthen the job skills of local government employees, update job information on the e-job website, and provide on-the-job training programs. Further research might usefully extend the present use of the TDMVM technique in order to investigate human resource quality within an enterprise, whereupon training becomes very important. This study suggests that the detailed study is needed that focuses on enhancing the training-implementing ability of an enterprise and assisting employees to enhance their career competitiveness effectively.

\section{References}

[1] Yang, T. M., Zheng, L., \& Pardo, T. (2012). The boundaries of information sharing and integration: A case study of Taiwan e-government. Government Information Quarterly, 29(1), S51-S60.

[2] Valdés, G., Solar, M., Astudillo, H., Iribarren, M., Concha, G., Visconti, M., et al. (2011). Conception, development and implementation of an e-government maturity model in public agencies. Government Information Quarterly, 28(2), 176-187.

[3] Beynon-Davies, P., \& Martin, S. (2004). Electronic local government and the modernisation agenda: Progress and prospects for public service improvement. Local Government Studies, 30(2), 214-229.

[4] King, S., \& Cotterill, S. (2007). Transformational government? The role of information technology in delivering citizen-centric local public services. Local Government Studies, 33(3), 333-354.

[5] United Nations e-government survey 2008: From e-government to connected governance. Retrieved November

2013,

from http://unpan1.un.org/intradoc/groups/public/documents/un/unpan028607.pdf

[6] Cappelli, P., (2001). Making the most of online recruiting. Harvard Business Review, 79, 139-146.

[7] Rust, R. T., \& Lemon, C. N. (2001). E-service and the consumer. International Journal of Electronic Commerce, 5(3), 85-101.

[8] Martilla, J. A., \& James, J. C. (1977). Importance-performance analysis. Journal of Marketing, 41, 77-79.

[9] Hu, H. Y., Lee, Y. C., Yen, T. M., \& Tsai, C. H. (2009). Using BPNN and DEMATEL to modify importance-performance analysis model - A study of the computer industry. Expert Systems with Applications, 36(6), 9969-9979.

[10] Coghlan, A. (2012). Facilitating reef tourism management through an innovative importance-performance analysis method. Tourism Management, 33(4), 767-775.

[11] Lo, C., Wang, C. H., Chien, P. Y., \& Hung, C. W. (2012). An empirical study of commercialization performance on nanoproducts. Technovation, 32(3-4), 168-178.

[12] Chang, C. (2013). Improving employment services management using IPA technique. Expert Systems 
with Applications, 40, 6948-6954.

[13] Lemieux, C. J., Thompson, J. L., Dawson, J., \& Schuster, R. M., et al. (2013). Natural resource manager perceptions of agency performance on climate change. Journal of Environmental Management, 114, 178-189.

[14] Chen, K. Y. (2014). Improving importance-performance analysis: The role of the zone of tolerance and competitor performance: The case of Taiwan's hot spring hotels. Tourism Management, 40, 260-272.

[15] Casper, R. (1985). Online recruitment. Personnel Journal, 64(5), 4-5.

[16] Hogler, R. L., Henle, C., \& Bemus, C. (1998). Internet recruiting and employment discrimination: A legal perspective. Human Resource Management Review, 8(2), 149-164.

[17] Cober, R. T., Brown, D. J., \& Levy, P. E. (2004). Form, content, and function: an evaluative methodology for corporate employment web sites. Human Resource Management, 43(2-3), 201-218.

[18] E-job website. Retrieved November, 25, 2013, from http://www.ejob.gov.tw/.

[19] Bureau of Employment and Vocational Training. Retrieved December, 25, 2013, from http://www.evta.gov.tw/eng/home/index.asp.

[20] Saraei, S., \& Amini, A. M. (2012). A study of service quality in rural ICT renters of Iran by SERVQUAL. Telecommunications Policy, 36(7), 571-578.

[21] Chen, L. F., Lin, S. P., \& Lin, C. Y. (2010). Application of IPA and back-propagation neural network to build a new service quality decision making model. International Journal of Information and Management Sciences, 21(3), 315-330.

[22] Parasuraman, A., Zeithaml, V. A., \& Berry, L. L. (1991). Refinement and reassessment of the SERVQUAL scale. Journal of Retailing, 67(4), 420-450.

[23] Alzola, L. M., \& Robaina, V. P. (2005). SERVQUAL: Its applicability in electronic commerce B2C. The Quality Management Journal, 12(4), 46-57.

[24] Kaisara, G., \& Pather, S. (2009). E-government in South Africa: E-service quality access and adoption factors. Informatics and Design Papers and Reports, Proceedings of the 11th Annual Conference on World Wide Web Applications (p. 26). Port Elizabeth, South Africa.

[25] Alanezi, M. A., Kamil, A., \& Basri, S. (2010). A proposed instrument dimensions for measuring e-government service quality. International Journal of u-International Journal of u-and e-Service, Science and Technology, 3(4), 1-17.

[26] Teicher, J., Hughes, O., \& Dow, N. (2002). E-government: A new route to public sector quality. Managing Service Quality: An International Journal, 12(6), 384-393.

[27] Buckley, J. (2003). E-service quality and the public sector. Managing Service Quality: An International Journal, 13(6), 453-462.

[28] Halaris, C., Magoutas, B., Papadomichelaki, X., \& Mentzas, G., et al. (2007). Classification and synthesis of quality approaches in e-government services. Internet Research, 17(4), 378-401.

[29] J. Zhuo, J., Chen, L. L., \& Li, F. B. (2009). E-S-QUAL: Its applicability in evaluating e-government web sites service quality. Proceedings of the International Symposium on Information Engineering and Electronic Commerce (pp. 515-518). Ternopil, Ukraine .

[30] Carmines, E. G., \& Richard, A. Z. (1979). Reliability and Validity Assessment. California: Sage Publications.

[31] Rafaeli, A. (1989). When clerks meet customers: A test of variables related to emotional expression on the job. Journal of Applied Psychology, 74(3), 385-393.

[32] Guilford, J. P. (1965). Fundamental Statistics in Psychology and Education. New York: McGraw-Hall.

[33] Vidot, J. (2000). Online Recruitment: Taking the Plunge. Retrieved December 27, 2013, from http://www.gradlink.edu.au/gradlink/employer/e_onlineartic.htm. 


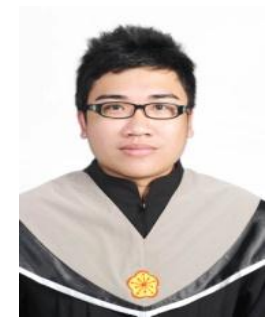

Chun-Ming Yang is a PhD Candidate in the Department of Management Sciences at Tamkang University in Taiwan. He earned his MS in the Department of Business Administration from Asia University. His research interests are in the field of process capability index and decision analysis. He has published in International Journal of Production Research, Proceedings of the Institution of Mechanical Engineers, Part B: Journal of Engineering Manufacture, and International Journal of Information and Management Sciences.

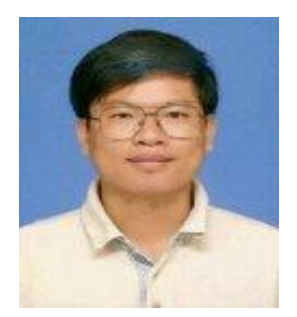

Neng-Yih Shin is an associate professor in the Department of Computer Science and Information Engineering at Asia University in Taiwan. He earned his $\mathrm{PhD}$ in the Department of Aeronautics and Astronautics from National Cheng Kung University. His research interests are in the field of intelligent control and data and system data modeling.

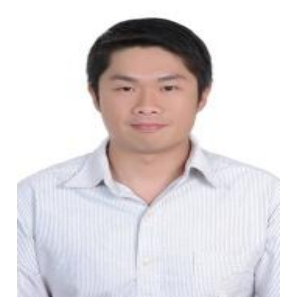

Ming-Wei Weng is an assistant professor in the Department of Industrial Engineering and Systems Management at Feng Chia University in Taiwan. His research interest lines in the field of the analysis of inventory system. He has publications in Production Planning \& Control, Computers \& Industrial Engineering, and Central European Journal of Operations Research.

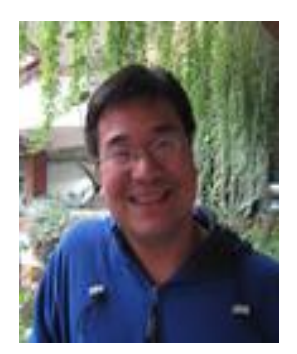

Quantity.

Chang-Hsien Hsu is an associate professor in the Department of Business Administration at Asia University in Taiwan. He earned his PhD in Graduate Institute of Management Science from Tamkang University. His research interests are in the field of process capability index and quality management. He has published in International Journal of Production Research, International Journal of Information and Management Sciences, Proceedings of the Institution of Mechanical Engineers, Part B: Journal of Engineering Manufacture, International Journal of Advanced Manufacturing Technology, and Quality \& 